\title{
Beyond the Equivalence Thesis: how to think about the ethics of withdrawing and withholding life-saving medical treatment
}

\author{
Nathan Emmerich ${ }^{1,2,3}$ - Bert Gordijn ${ }^{2}$
}

Published online: 13 February 2019

(c) Springer Nature B.V. 2019

\begin{abstract}
With few exceptions, the literature on withdrawing and withholding life-saving treatment considers the bare fact of withdrawing or withholding to lack any ethical significance. If anything, the professional guidelines on this matter are even more uniform. However, while no small degree of progress has been made toward persuading healthcare professionals to withhold treatments that are unlikely to provide significant benefit, it is clear that a certain level of ambivalence remains with regard to withdrawing treatment. Given that the absence of clinical benefit means treating patients is not only ethically questionable but also taxing on resources that could meet the needs of others, this ambivalence is troubling. Equally, the enduring ambivalence of professionals might be taken to indicate that the issue warrants further attention. In this paper, we review the academic literature on the ethical equivalence of withdrawing and withholding medical treatment. While we are not in outright disagreement with the arguments presented, we suggest that asserting theoretical and decontextualized claims about the ethical equivalence of withdrawing and withholding life-saving treatment does not fully illuminate the moral questions associated with the relevant clinical realities. We argue that what is required is a broader perspective, one rooted in an understanding that withdrawing and withholding lifesaving treatment are different practices, the meanings of which are fully comprehensible only through an appreciation of their place within the practice of healthcare more generally. Such an account suggests that if one is to engage with the inappropriate protraction of life-saving treatment resulting from healthcare professionals' disinclination to withdraw it, then the differences between these practices should be taken seriously.
\end{abstract}

Keywords Equivalence Thesis · Withdrawing - Withholding · Medical practice · Acts and omissions

Nathan Emmerich

nathan.emmerich@anu.edu.au

Extended author information available on the last page of the article 


\section{Introduction}

This paper addresses the issue of withdrawing and withholding life-saving treatment and what we see as the maladaptive ethical discourse that surrounds it. Despite the fact that a preponderance of academic commentators [1-5] and professional guidelines [6,7] consider the difference between withdrawing and withholding life-saving treatment to lack any moral significance, it is clear that, in practice, this distinction carries a certain degree of moral weight [8, 9]. It seems that one of two things is true. On the one hand, there may be nothing significantly wrong with the communis opinio in the academic literature and professional guidelines. Yet while healthcare professionals have, when appropriate, been willing to withhold potentially life-saving treatments, they seem significantly less willing to withdraw such care. Thus, some patients are subject to an inappropriate degree of treatment. On the other hand, the academic discourse and professional guidelines on the ethics of withdrawing and withholding life-saving treatment may instead be misguided. If this is the case, it would seem that the current approach fails to account for some morally significant component of the withdrawal of life-saving treatment. There appears to be a widespread assumption that the first of these alternatives is correct and there is nothing wrong with the current consensus. The discrepancy between withdrawing and withholding is explained by reference to the moral psychology of healthcare professionals-it is a function of their psychosocial response to withdrawing care. Such psychosocial responses are then dismissed as factors that should not inform ethical evaluations. Given this view, commentators find themselves unable to do more than suggest that healthcare professionals be provided with further instruction on the matter $[8,10]$.

In contrast to this picture, we argue that the ethical analysis of withdrawing and withholding life-saving treatment relies on a misguided conception of action, one that underpins the way cases are structured and understood in the discourse of applied ethics. While this might provide a fruitful approach in the domains of analytic moral philosophy and applied ethics, it is less than useful when the accounts developed within these fields are expected to be carried forward into clinical practice. At least in part, the problem can be traced to the Equivalence Thesis (ET). Emerging from debates about the difference, or lack thereof, between killing and letting die, between acts and omissions-debates that were primarily concerned with ethical questions about euthanasia-the ET has since come to be applied to withdrawing and withholding life-saving treatment. We propose an alternative approach to the analysis of withdrawing and withholding life-saving treatment, one that is based on practice theory. This approach seems more consistent with the complexity of clinical practice.

While its roots can be traced to the advent of ethnomethodology as well as to early sociology of scientific knowledge (SSK) and science and technology studies (STS), practice theory is possibly the most significant development in social theory of the past twenty-five years or so [11]. Furthermore, though there is no unitary "practice theory" [12], the family of accounts that fall within its purview 
offer interpretations of social life that show a highly sophisticated and philosophically informed understanding of the way in which we lead our lives. This is particularly true of theories that are clear about their phenomenological and Wittgensteinian influences. While we do not provide a full exposition of practice theory here, our discussion of the theory's basics, presented below, should allow the reader sufficient grasp of the fundamentals of this perspective, at least for the purposes at hand. At this juncture, it is worth noting that practice theory's rejection of any restriction of focus to what might be called the "act itself" [13] has particular significance. It entails a rejection of the notion that acts can be fully understood as temporally located events, a perspective that seems to be dominant in applied philosophical ethics. Instead, the social, cultural, and historical structure of acts must be appreciated, particularly when the focus is on those that are situated within a broader practice such as medicine. The (moral and clinical) agency of medical doctors is not just a matter of free will; it is constrained by such structures, delineating between what is and is not proper to contemporary medical practice. Thus, in practice theory, the focus is on "arrays of human activity" that are constituted within particular fields [14, p. 11]. Furthermore, proponents of practice theory

usually acknowledge the structuring and coordinating import of agreements, negotiations, and other interactions, as well as the undergirding significance of skills and interpretations. They treat these phenomena, however, as features of or as embedded in practices, hence as subject to or as constitutive of the latter. As a result, interactions, skills, and interpretations determine orders (and are themselves ordered) qua features of practice. [14, p. 14]

We take this view to suggest that the practices of withdrawing and withholding lifesaving medical treatment inhabit or are part of a broader practice, that of medicine and healthcare as a whole. As such, what counts, first, as an instance of withdrawing or withholding and, second, as an instance of good or bad (rightly or wrongly pursued) withdrawing or withholding is defined by or within the field. ${ }^{1}$ Thus, we suggest that withdrawing and withholding should be understood as situated within their wider social, cultural, and institutional contexts.

The outline of this paper is as follows. First, we sketch the history of the bioethical and medical ethical debate surrounding these clinical practices. We then point out the problematic issues arising from the application of the ET to those practices and discuss withdrawing and withholding life-saving treatment from the perspective of practice theory. Finally, we lay out an alternative, contextualized approach to the ethics of withdrawing and withholding life-saving treatment, which is more in tune with the reality of clinical practice.

\footnotetext{
1 The concept of a field is an indispensable part of practice theory. It is particularly important to note that a field is not simply a generalized arena of social interaction; it is a broader, more abstract notion, which includes what Neil Fligstein and Doug McAdam term "internal governance units" [15].
} 


\section{A historical sketch of the academic debate on withdrawing and withholding life-saving treatment}

In a certain sense, issues related to withdrawing and withholding treatment have been part of bioethics since its inception. While usually framed in terms of resource allocation, one of the first truly bioethical questions, the question of which patients should receive dialysis can, for example, be understood as a matter of determining from which patients it should be withheld. Furthermore, in her historical account of the field, Tina Stevens argues that the first glimmers of bioethics in the 1950s and 1960s can be traced to, among other things, concerns about attempts to save lives that often did little more than prolong dying [16]. According to another historian, David Rothman, the question of when life support machines should be switched off-which is to say, withdrawn-similarly troubled doctors [17]. This might be taken to indicate that questions regarding withdrawing and withholding life support were among the first to be addressed by bioethical thinking. However, at the time, the intensive care unit was a "private domain" in which doctors "exercised their discretion" [17, p. 160]. There was, then, no pressing need to create appropriate criteria for the withdrawal of treatment.

Instead, a number of other avenues were explored, not least the idea of brain death. Defining death as brain death effectively sidestepped the need to determine when care should be withdrawn [18, 19], as borne out by comments made in a 1983 report by the President's Commission for the Study of Ethical Problems in Medicine and Biomedical and Behavioral Research [20]. The authors of this report, entitled Deciding to Forego Life-sustaining Treatment, point out that the Commission's first report, Defining Death [21], stated "an intention to report subsequently on the treatment of patients who are dying but not dead" [20, p. 10]. This might be taken to suggest that, having adopted brain death as the definition of death, thereby sanctioning the withdrawal of treatment from this class of patients, the Commission rapidly acted to extend their thinking so as to account for those who were not dead but would never regain consciousness. However, one ought to bear in mind that the formal criteria for brain death, which were published in JAMA in 1968 [22], had been in use for more than a decade by the time these reports were written. Finally, while the 1983 report discusses the withdrawal of treatment from those who do not meet the criteria for brain death but whose condition means they will not regain consciousness, its primary concern is with "the situations in which a patient's choice to forego life-sustaining therapy may be limited on moral or legal grounds" [20, p. 2].

For the most part, then, early bioethics appears to have eschewed direct consideration of the ethics of withdrawing and withholding life-prolonging treatment. The topic is often mentioned briefly but not subject to detailed examination. For example, in his influential Causing Death and Saving Lives [23], Jonathan Glover discusses various matters related to withdrawing and withholding life-saving medical treatment, including the doctrine of acts and omissions, the question of euthanasia, and, most pertinently, the problem of "not prolonging dying" [23, p. 197]-the title of a section in his chapter on euthanasia without request-without explicitly 
touching on either withdrawing or withholding. ${ }^{2}$ Similarly, while some attention is paid to withdrawing and withholding in the 1983 report by the President's Commission, its stated focus is whether or not a patient's choice to forego life-saving treatment is subject to limitations [20]. Likewise, although he is writing in the first half of the 1990s, David Lamb's [24] preference for the term therapy abatement arguably evinces a comparable reluctance to discuss the matter on its own merits. A similar inclination can be detected in Harris's influential text The Value of Life [25]. Rather than discuss withdrawing and withholding, he prefers to speak of "selective nontreatment" [25, p. 33]. Furthermore, he addresses the topic only briefly and, as is common in the bioethics literature, largely does so in the interest of advancing an argument about euthanasia. The literature has shown a clear preference for discussing a number of distinctions later related to questions of withdrawing and withholding treatment. At least initially, and perhaps still, such discussions prioritized questions related to killing, letting die, and euthanasia [26, 27] as well as the doctrine of acts and omissions $[28,29]$. Ultimately, this early literature has directly shaped the ways in which the issues of withdrawing and withholding are set out and discussed in contemporary bioethics (cf. [4]).

Thus, ethical questions about withdrawing and withholding tend to be addressed alongside, and in the light of, debates and distinctions largely associated with other issues and questions. This arguably remains a feature of present debates; the withdrawal and withholding of treatment continue to be discussed primarily in relation either to questions of killing and letting die or to questions of active and passive euthanasia. Indeed, these questions have not only had priority over debates regarding withdrawing and withholding treatment, but have also come to shape the field and conduct of bioethical scholarship. More often than not, entering the field means getting to grips with such distinctions and, in particular, the ways in which they are thought to relate to one another. As such, they are central to the particular mode of thought that defines applied ethics, the dominant bioethical discourse [30].

Our claims about the way in which withdrawing and withholding life-saving treatment has been debated find support in the second edition of Bioethics: An Introduction to the History, Methods, and Practice [31]. ${ }^{3}$ The volume includes a section on "Withholding and Withdrawing Medical Treatment" [31, pp. 400-426], which is absent from the prior edition [32]. ${ }^{4}$ Furthermore, Robert McCormick's and James Rachels' essays, which are contained in a section entitled "To Save or Let Die" in the first edition, are refiled in the second edition under a section called "The

\footnotetext{
${ }^{2}$ We are grateful to one of this journal's reviewers for reminding us of this text and its importance, particularly with regard to its influence on others, including John Harris-whose work we subsequently discuss - who attended the seminars in which Glover first developed his argument.

${ }^{3}$ Per a query by one of our reviewers, it is worth pointing out that we do not mean to suggest that this particular book is somehow central to understanding bioethics; acquaintance with it is not indispensable to those working within the field. That said, one could hardly get to grips with the field without encountering a book of this sort and at least some of the essays collected within it. Rather like many such collections and introductory texts, this volume seeks to set out the range and scope of bioethics. In so doing, it offers a sketch of the field's sense of itself, a fact that is consistent with the point we are trying to make.

4 Apart from a minor reordering of chapters, the section remains unchanged in the third edition [33].
} 
Emergence of Bioethics as a Discipline and Discourse" [31, pp. 17-80]. This development again indicates the degree to which questions about withdrawing and withholding treatment have been framed by debates about euthanasia, killing, and letting die-debates that are accorded greater significance and priority in the literature. ${ }^{5}$ They are seen as landmarks in the field and, as indicated by their inclusion in collections such as the one under discussion, their arguments are often taken as exemplary, defining discourses that offer instruction to the field of bioethics as a whole as regards both ethics and methodology.

\section{The ET and its problematic application to withdrawing and withholding life-saving treatment}

While they draw on the thinking presented in earlier literature, Daniel Sulmasy and Jeremy Sugarman seem to have formulated the first explicit statement of the ET in the context of withdrawing and withholding life-saving treatment [34]. ${ }^{6}$ Nevertheless, the authors present the ET as though it were already established as an accepted part of the literature, although this may reflect the view that such a thesis is implicitly presumed, rather than explicitly stated, in previous work. They say that:

Stated precisely, the Equivalence Thesis we wish to examine asserts that:

1. If it would have been morally permissible to have withheld a therapy (that has in fact already been started), then it is now morally permissible to withdraw that therapy.

and

2. If, in the future, it would be morally permissible to withdraw a therapy (that has in fact not yet been started), then it is now morally permissible to withhold that therapy. $[34]^{7}$

Dominic Wilkinson and Julian Savulescu later provide a slightly different statement of the same thesis, saying that:

\footnotetext{
5 Indeed, the moral equivalence of withdrawing and withholding life-saving treatment is often an explicit premise in the ethical analysis of assisted suicide (cf. [1]).

${ }^{6}$ In a personal communication with the authors, Sulmasy and Sugarman suggest that, while they cannot be certain, they may have coined the Equivalence Thesis in their article [34]. Furthermore, they say that they do not recall having read Frances Kamm or Judith Lichtenberg prior to writing their paper but acknowledge that they would certainly have read Rachels.

7 In this formulation, Sulmasy and Sugarman fail to mention the significance of the ceteris paribus clause. For example, while it is permissible to withhold care on the legitimate expectation that this care would not benefit the patient, the ET does not suggest that it is permissible to withdraw care if this care happens to be having an unexpectedly positive effect.
} 
Other things being equal, it is permissible to withdraw a medical treatment that a patient is receiving if it would have been permissible to withhold the same treatment (not already provided), and vice versa. We might contrast this with Non-Equivalence. ... Even where other things are equal, it is sometimes permissible to withhold treatment from a patient though it would not be permissible to withdraw the same treatment if already started. [35]

As they make clear in a footnote, Wilkinson and Savulescu consider this to be a restatement of the so-called bare difference argument-the idea that the bare difference between withdrawing and withholding lacks any moral significance. As will be discussed further, this idea can be traced to James Rachels' landmark article "Active and Passive Euthanasia" [26], where is it used in the context of killing and letting die. As such, one might question the soundness of transposing an argument from this removed context and resituating it as something of direct relevance to withdrawing and withholding life-saving treatment without some deeper reflection on the issue.

Consider the fact that neither the withdrawal nor the withholding of life-saving treatment constitutes killing [36]. While the withdrawal of treatment might involve some kind of action - the removal of a ventilator, say - it does not amount to killing per se. After all, there is no active intention to cause the patient's death. Rather, having concluded that the ends of treatment are no longer achievable and that death is unavoidable, medical professionals elect not to further interfere with the dying process. The most that can be said in such cases is that, in acting this way, they let or allow the patient to die.

Those who advance the view that there is no significant ethical difference between withdrawing and withholding life-saving treatment rely on the ET. Many authors-including Baruch Brody [37]; Arthur Derse [38]; Thomas Huddle [39]; Nancy Jecker and Linda Emanuel [40]; Frances Kamm [27]; Helga Kuhse [41]; Franklin Miller, Robert Truog, and Dan Brock [42]; Laurence Thomas [29] ${ }^{8}$; and Roy Perrett [44] - seem to attribute the ET or the idea that there can be a moral equivalence between acts and omissions (and, therefore, between acts of withdrawing and omissions of withholding life-saving treatment) to the aforementioned essay by Rachels [26]. However, as noted, Rachels' essay concerns not withdrawing and withholding life-saving treatment but the distinction, or lack thereof, between active and passive euthanasia. Furthermore, although Rachels subsequently discusses the ET and presents the bare difference argument as a central plank in its favor [45-48], "Active and Passive Euthanasia" itself contains no mention of the ET [26]. Indeed, this thesis-namely, that there is no ethical significance attached to the distinction between killing and letting die-is instead termed the bare difference argument.

The bare difference argument has since been presented in the context of a range of examples, including thought experiments such as the bathtub case, certain trolley cases, and so forth. While many of these might be considered philosophically convincing, the example Rachels presents in his original article is, perhaps, most

\footnotetext{
8 Thomas considers those who advocate for what he calls the doctrine of the moral equivalence of acts and omissions, particularly Rachels [26] and Lichtenberg [28], as treating it as a "pre-theoretical moral truth" [29]. He also cites a collection of essays edited by Bonnie Steinbock as some of the most important papers written on the topic [43].
} 
compelling. Rachels discusses instances in which babies born with Down syndrome were allowed to die. He suggests that this practice is, in reality, a form of passive euthanasia and should therefore be seen as no more or less reprehensible than the active killing of such patients. Indeed, given the additional suffering incurred when passively letting a baby die, as compared to actively ending its life, the former may be worse than the latter [26].

Of course, cases in which babies with Down syndrome are allowed to die are cases in which life-saving treatment is being withheld. This was not a general policy, and only babies born with certain additional (common and treatable) medical problems, such as intestinal blockage, were left untreated and allowed to die. That actual instances of this practice in fact occurred is an undiscussed precursor to Rachels' use of this example.

As well as making no mention of the ET, Rachels' essay does not discuss the withdrawing or withholding of treatment. However, starting with his 1979 essay "Killing and Starving to Death," Rachels begins to present the bare difference argument as something offered in support of the ET [45, 46]. ${ }^{9}$ For example, in his 1986 book The End of Life: Euthanasia and Morality [47], Rachels reiterates the bare difference argument and, in so doing, sets out the ET in relation to killing and letting die. A section entitled "The Bare Difference Argument" starts as follows:

The Equivalence Thesis, as I will call it, says that there is no morally important difference between killing and letting die; if one is permissible (or objectionable), then so is the other, and to the same degree. More precisely, it is a claim about what does, or does not, count as a morally good reason in support of a value judgement: the bare fact that one act is an act of killing, while another act is an act of 'merely' letting someone die, is not a morally good reason in support of the judgement that the former is worse than the latter. [45, p. 111] ${ }^{10}$

Nevertheless, the earliest mention of the ET we have found occurs in Rachels' 1979 publication, and while Rachels makes easy use of the phrase, as though it were something readers would be familiar with, we have not found a prior example of its use. Indeed, in a 1983 article, Kamm discusses the claim that killing and letting die are morally equivalent and refers to this as "Thesis E" [27]. Of course, the E of Thesis E stands for equivalent, but the fact that Kamm refers to the idea in this way seems to indicate that philosophers and applied ethicists had not uniformly adopted the Equivalence Thesis as a terminological standard. The term does, however, appear elsewhere, such as in an essay by Lichtenberg entitled "The Moral Equivalence of Action and Omission" [28]. Published in the Canadian Journal of Philosophy's supplementary volume for 1982, this essay makes scattered reference to the "equivalence

\footnotetext{
9 It is worth making clear that although it is entitled "Killing and Starving to Death," Rachels' 1979 essay is concerned not with medicine or healthcare, but with our moral responsibilities toward those experiencing famine [46].

${ }^{10}$ Of course, Rachels is not suggesting that "every act of letting die is equally as bad as every act of killing," merely that "whatever reasons there may be for judging one act worse than another, the bare fact that one is killing, while the other is letting die, is not among them" [45, p. 111].
} 
thesis" throughout (e.g., [28, pp. 26, 32]); yet another essay contained in the same supplementary volume makes no use of the phrase at all, instead critiquing what its author calls the increasingly popular doctrine of the moral equivalence of acts and omissions (MEAO) [29, p. 39]. Together, these differences might be taken as indication that the ET is the product of a gradual process in which contemporary philosophical thinking about morality and ethics coalesced around a particular philosophical position concerning the moral status of acts and omissions, itself informed by an analysis of the distinction between killing and letting die.

The complex origins of the ET are significant for our discussion of withdrawing and withholding treatment. Given that neither withdrawing nor withholding treatment involves actively killing patients - both should be considered instances of letting dieone might think that Rachels' formulation of the ET reveals little about their moral equivalence. Thus, arguments about withdrawing and withholding treatment are not direct applications of the ET. Rather, they involve its reiteration and, as a result, represent a further development. As such, they should be reconsidered. To this end, one might begin by replacing the terms killing and letting die in statements of the ET with the terms withdrawing and withholding life-saving treatment:

There is no morally important difference between withdrawing and withholding life-saving treatment; if one is permissible (or objectionable), then so is the other, and to the same degree. ... The bare fact that one act is an act of withdrawing life-saving treatment, while another act is an act of merely withholding life-saving treatment, is not a morally good reason in support of the judgment that the former is worse than the latter. (adapted from [45, p. 111])

While this adaptation might seem sensible, there is, we think, reason to resist such a formulation. To start, one might consider the reasons used to justify the withdrawal or withholding of life-saving treatment - the most significant of which is the notion that such treatment does not, in fact, have the potential to save the patient's life. In some cases, such treatments may preserve the life of the patient, maybe even indefinitely; but the withdrawal or withholding of treatment is considered because, while it may be possible to preserve or maintain the patient's biological life, there is little to no prospect of prolonging the patient's biographical life. Further reflection on this point leads to the complex terrain of futility (cf. [49]), which, for reasons of space, we must forego. ${ }^{11}$ We do, however, take this point to suggest that withdrawing and withholding life-saving treatment are not the correct focus if the ET is to be respecified. Instead, the focus should be on the more general notions of making and allowing [43] or, better yet, doing and allowing [50]. In so adopting this focus, the appropriate level of generality can be attached to the ET as a philosophical principle. As a result, the acts of withdrawing and

\footnotetext{
11 One could take the concept of futility to suggest that talk of withdrawing or withholding treatment should be abandoned. Treatment is not treatment if it is futile, and if treatment is not futile, then it should not be withdrawn or withheld. However, on pain of practical irrelevance, the concept of futility cannot be restricted in the way required; while philosophical discussion can be predicated on certainty, medical practice cannot. This point further suggests that withdrawing and withholding life-saving treatment should be understood not in purely conceptual terms but as forms of medical practice, thus falling within the scope of practice theory.
} 
withholding life-saving treatment could be considered to fall within the purview of the ET, albeit while their complexity is temporarily placed to one side. Indeed, although we do not argue the point, it may be advisable to make a similar move in the context of killing and letting die. The fact that the differences between killing and letting die cannot ground any moral distinction does not mean they should be used in any statement of the ET. Rather, the absence of any necessary moral distinction between killing and letting die should be seen as an implication of the ET stated in terms of doing and allowing. Thus, the ET can be restated as follows:

There is no morally important difference between doing and allowing; if one is permissible (or objectionable), then so is the other, and to the same degree.... The bare fact that one act involves action [doing], while another act involves inaction [allowing], is not a morally good reason in support of the judgement that the former is worse than the latter. (adapted from [45, p. 111])

This statement elucidates the fact that the ET represents the moral implications of the doctrine of acts and omissions. The nature of human action is such that omissions (inactions) are, nevertheless, things that we allow to happen; they are courses of action that we elect to pursue. Thus, the claim that inaction is immune from moral evaluation cannot be maintained. The implications of this are, of course, complex. Understood simplistically, one might think we are constantly engaged in any number of inactions. For example, at this present time, we are not walking a dog, attending to our emails, or reading Shakespeare. We are also not donating blood or our left kidneys, nor are we giving money to developing-world countries. The latter examples are actions that could save lives; yet most would be reluctant to say that by not doing these things we are allowing individuals to die. Notwithstanding such difficulties, the bare difference between some event that involves an act (making or doing) and another event that is, in every other respect, the same but involves an omission (allowing) renders them ethically equivalent. In our view, the bathtub case establishes this point, at least theoretically, since only one defensible example is required to establish the fact that the bare difference between the act of killing and the omission of letting die lacks moral significance. Nevertheless, it may yet be the case either that certain kinds of action-and-omission pairs are such that an ethical distinction can be introduced or that there is a legitimate reason for thinking that one such pair (i.e., killing or withdrawing life-saving treatment) should attract greater moral concern than another (i.e., letting die or withholding life-saving treatment).

Indeed, as the above discussion suggests, even if one accepts that omissions areor, at least, can be-acts, one should not necessarily eliminate the term omission, which continues to serve as a useful label for a certain class of action. While the ET might be taken to be theoretically established qua acts and omissions, one should be wary of using a purely philosophical account in regard to particular act-omission pairs. Social life is more than a series of acts; rather, much of what we do is constituted by and in practice. If one is to properly characterize the ethical significance of an act-omission pair, such as that of withdrawing and withholding life-saving medical treatment, then its component parts should be examined in more detail. 


\section{Practice theory}

In the literature on medical ethics and bioethics, significance is often attached to the implications that a particular ethical viewpoint or argument might have for practice. The notion of practice operative within applied ethics — and, therefore, philosophical bioethics - which is invoked when assessing the value of arguments, concerns the degree to which a proffered ethical analysis can be used to condition or reconstruct that which takes place within the clinic. Concern for the practical implications of bioethics suggests that bioethical insights can dictate or otherwise structure the actions or courses of action that should be pursued by clinicians. However, the point is primarily epistemic. Any (bio)ethical analysis of a particular case sets out the way in which that case ought to be understood, whether explicitly or implicitly. Questions about the extent to which certain philosophical points can be maintained in the clinical context, or in practice, do not receive widespread consideration. ${ }^{12}$ Thus, while it may indeed be the case that the patient should not be treated if there is no prospect of success, it is also the case that, in practice, healthcare professionals are rarely certain about the (im)possibility of success. Furthermore, death may not be the only possible negative outcome, and differences may exist between success and mere survival, given that for many patients some forms of survival can be unacceptable [51]. The philosophical forms of analysis pursued by applied (bio)ethicists rarely, if ever, reflect the degree of prognostic and practical uncertainty involved in clinical practice. $^{13}$

Such concerns are, of course, important. Nevertheless, they differ from the line of thought we now pursue under the heading of practice theory, ${ }^{14}$ something that is used as an umbrella term for an influential set of ideas in contemporary social theory. ${ }^{15}$ Rather than consider the relevance of applied ethics for clinical practice, we consider the withdrawal and withholding of life-saving treatment not as simple or discrete events or acts but as phenomena embedded within the practice of modern healthcare - that is, as practices in the sense conveyed by the idea of practice theory. ${ }^{16}$ While the notion of practice theory cannot be reduced to a single, unitary philosophy, instead functioning as a relatively broad label for a range of theoretical perspectives,

\footnotetext{
12 See the points made in fn. 11.

13 On the nature of prognostic uncertainty in medical practice and care at the end of life, see Nicholas Christakis [52].

14 We do not mean to suggest that there are no examples of moral philosophy or applied ethics that discuss practice in a manner similar to the perspective offered by what we are calling practice theory. Certainly, Alasdair MacIntyre's discussion of both practice and tradition is one such example [53-55]. Similarly, not least because of their Wittgensteinian commitments, the philosophical works of both Peter Winch $[14,56,57]$ and Stephen Toulmin $[12,14]$ can be understood, broadly speaking, as aligning with practice theory; and, of course, both scholars have things to say about morality and ethics. However, it is important to note that, for the most part, talk of practice in the bioethical literature is not equivalent to talk of practice in social theory. Perhaps the closest example of bioethical scholarship that moves in the direction we discuss is Judith Andre's work Bioethics as Practice [58].

15 Nigel Pleasants considers the discourse of social theory to lie somewhere between the social sciences and philosophy and, furthermore, considers Winch to be "a founding contributor" to this field, discipline or mode of thought [59].

16 For an overview of practice theory, see Joseph Rouse [12] and, in anthropology, Sherry Ortner [11].
} 
practice-theoretic accounts do exhibit a certain degree of family resemblance. In general, practice theory represents an attempt to understand how human activities produce and reproduce the social structures, fields, and worlds that they inhabit, while at the same time recognizing how social worlds produce and reproduce the human actors, actions, and activities that they contain [15]. At their most basic, practice theories relate or reconcile the sociological antinomies of structure and agency through the concept of practice. As such, practices - and the fields within which they are constituted-become the defining feature of what Wittgenstein calls forms of life but what is, perhaps, better termed, after Winch [57], modes of social life. ${ }^{17}$

Accounts that focus on acts and those that focus on practices entail certain philosophical differences regarding the way in which the social world is understood. A social ontology predicated upon social practices is incommensurable with one that is predicated upon acts. However well described, a series of acts does not add up to a practice, and a practice cannot be reduced to a series of acts; practices are greater than the sum of their parts. If they are to be grasped fully, the withdrawal and withholding of life-saving treatment cannot be represented simply as acts that occur at particular times and in particular places. To represent them in this way would be to define the Tour de France by the final sprint down the Champs-Élysées or to define climbing a mountain by the point at which climbers reach the summit. Rather, withdrawing and withholding life-saving treatment are aspects of medical practice, ones that are informed, structured, and coordinated by various agreements, negotiations, and interactions. In addition, these agreements, negotiations, and interactions should be understood as features of the practice that not only order but are also ordered by the practice. In short, a proper understanding of the practices of withdrawing and withholding life-saving treatment should encompass such ordering activities - that is, the wider discussions and negotiations that bring about the act of withdrawing or withholding treatment.

This perspective can be focused at differing levels. In particular instances of withdrawing and withholding life-saving treatment, one can concern oneself with the relevant social interactions that occur among healthcare professionals and those that occur between healthcare professionals and non-professionals, notably patients and their families. In some cases, such interactions might also include those with ethics committees, legal advisors, and law courts. However, if a broader, macro perspective is adopted, then one might consider the way in which legal and professional guidelines structure the practices of withdrawing and withholding life-saving treatment and the way in which ethical analysis offered by academics, set the conditions for clinical practice. Such prior activities, along with the social and professional structures that they establish, are relevant to a full understanding of withdrawing and withholding life-saving treatment. ${ }^{18}$ In setting the ethical contexts in which

\footnotetext{
17 The way in which such notions can be related to MacIntyre's conception of a practice or, more accurately, a tradition indicates the diversity of practice theory as well as something of the family resemblances that hold such accounts together as theories of practice. It is also suggestive of their relevance to moral philosophy on the one hand and to the substantive ethics internal to particular practices, traditions, or modes of social life on the other. See fn. 14.

18 Of course, neither scholarly analyses of the ethics of withdrawing and withholding life-saving treatment nor the professional guidelines that inform such practices can really be thought of as being prior to medical practice. The fact that bioethicists attend to the problem, together with the fact that professional
} 
treatment is withdrawn or withheld, they contribute to the ethical significance of particular instances or cases in which treatment is withdrawn or withheld.

As we suggest above, philosophy and applied ethics operate (and ought to operate) at a relatively high level of generality. In our view, this level of generality should be taken to rule out a specification of the ET in terms of withdrawing and withholding life-saving treatment, not least because such acts, actions, activities, or practices exhibit a high level of contextual (social, cultural, and historical) circumscription. Just as surgery can only be undertaken by a surgeon, so too can withdrawing and withholding life-saving medical treatment only take place in the context of professional clinical practice. In this way, the ethics of withdrawing and withholding life-saving treatment should be understood in terms of the situated practices that constitute them. The particular ethical significance of the terms withdrawing and withholding in this essay is, then, a function of their relation to life-saving medical treatment as part of professional clinical practice.

As such, particular instances of withdrawing and withholding life-saving medical treatment can and should be evaluated in accordance with normative standards of professional practice. Such evaluations can be conducted in relation to the formal guidelines that have been specifically articulated with regard to withdrawing and withholding treatment $[6,7]$, as well as in terms of more general professional principles, such as those set out by the United Kingdom's General Medical Council in their document Good Medical Practice [60]. Indeed, more than providing for the evaluation of withdrawing and withholding, such documents set out-which is to say, they constitute - the practice itself. In this way, the practices of withdrawing and withholding life-saving medical treatment bear a specific relation to medicine and healthcare, understood as particular modes of social life [57]. ${ }^{19}$ The terms do not, then, have the same meaning or ethical significance when used in other nonmedical contexts or when used by those who do not inhabit this mode of social life. This is to say that, properly understood, treatment cannot be withdrawn or withheld by those who are not healthcare professionals. Thus, because they are agent-relative practices, the conceptual couplet of withdrawing and withholding-when compared to killing and letting die, acts and omissions, or doing and allowing - is, at minimum, far less suited to being used in the manner required by the ET, and to do so may well be inappropriate.

To be clear, this point is not meant to rule out the possibility that some articulations of the ET have some form of relevance to discussions about the ethical acceptability of withdrawing and withholding life-saving treatment. Our position is that, with regard to the matter of killing versus letting die, the ET is reasonably

\footnotetext{
Footnote 18 (continued)

guidelines have been developed to structure what takes place in practice, indicates that the issue already has some degree of clinical reality. As such, academic analyses, professional guidelines, and the realities of practice are mutually interrelated, not least through the entanglement generated by the respective practices involved in clinical medicine, the pursuit of bioethics, and the development of professional ethical guidelines.

19 Further detail on the way Winch understands modes of social life can be found in the preface to The Idea of a Social Science and its Relation to Philosophy [57, pp. ix-xvii].
} 
informative. One might think that the illumination offered by the ET also carries over into debates about acts versus omissions and doing versus allowing. Positions within these debates are, of course, relevant to philosophical discussion of the withdrawing and withholding of life-saving treatment. Nevertheless, restating the ET in terms of withdrawing and withholding life-saving treatment is, we suggest, misguided. Our reasoning is that while killing and letting die, say, can be understood in a restricted sense, as specific acts or events, withdrawing and withholding lifesaving treatment need to be understood in relation to medical practice and, therefore, in the broader terms offered by practice theory.

The implications that stem from adopting a practice-based account of withdrawing and withholding life-saving treatment are complex, particularly when it comes to the way in which its ethical dimensions should be considered. Our understanding of practices such as cycling the Tour de France or mountain climbing are not restricted to the activities themselves but encompass a range of peripheral inputs, including apparent antecedents such as the construction of equipment (e.g., cycles, crampons) and the preparatory activities that support such endeavors (e.g., cycling teams, altitude training). Furthermore, we might also include broader, but nevertheless related, practices, such as support teams and mountain rescue, which facilitate the specific practices in question and step in when they go wrong. Given this view, the ethics of withdrawing and withholding life-saving treatment should attend to more than just the specific climactic event. Rather, attention should be paid to the broader context and social structures that condition and shape particular cases or instances. This view suggests that the withdrawal and withholding of life-saving treatment are related to one another. Certainly, they are constructed in light of one another. Nevertheless, it also suggests that the ceteris paribus clause required by the ET cannot be maintained. The requisite and relevant activities that lead up to the two events or acts necessarily differ precisely because one is a case of withdrawing and the other is a case of withholding; when it comes to withdrawing or withholding life-saving treatment in reality, no case of the former is ever entirely equivalent to a case of the latter.

\section{Withdrawing and withholding life-saving treatment as practices}

Our position is that it is not possible to make a complete ethical assessment of withdrawing and withholding life-saving treatment unless one grasps the way in which these decisions are situated and made in practice; that is to say, it is necessary to grasp how life-saving treatments and the ways in which they are withdrawn and withheld are configured by, and within, the practices of contemporary medicine and clinical decision-making. However, both as a matter of principle and for reasons of space, it is not possible to present a full account of these practices. Indeed, the best way to do so would be to undertake an ethnographic study, and those that have been conducted in certain relevant contexts are highly illuminating [61-65]. We do not, then, offer an exhaustive account of the practices of withdrawing and withholding life-saving treatment. Indeed, we are not entirely sure that it is possible to do so. 
Instead, in this section, we provide some general characterizations, and points of contrast, regarding withdrawing and withholding life-saving treatment.

As we have argued, the ceteris paribus condition rarely, if ever, obtains for actual cases of withdrawing and withholding life-saving treatment. Certainly there will be some cases where a number of parallels might be found. Nevertheless, while in certain cases the withdrawal of life-saving treatment could be considered comparable, in a relatively exacting sense, to the withholding of life-saving treatment, at the very least, the clinical picture-or, one might say, the epistemic perspective of the concerned healthcare professionals-will have changed at some point earlier. Indeed, even if it is only a matter of increased clarity or decreased uncertainty, this change is significant; the presence of prognostic uncertainty gives reason to think that withdrawing life-saving treatment may be preferable to withholding it [66]. Those who favor applying the ET to withdrawing and withholding life-saving treatment directly might, at this juncture, object. They might be inclined to point out that the ET neither suggests that there are nor relies upon there being any actual cases in which withdrawing life-saving treatment is equivalent to withholding life-saving treatment. Indeed, they might say not only that the theoretical validity of the ET is all that matters but also that it would be just as unusual for any actual cases of killing and letting die to be equivalent to one another.

Our response, however, would be to reiterate our commitment to viewing withdrawing and withholding life-saving treatment as practices that are situated within modern medical practice as a whole. The terms killing and letting die name particular acts, while the terms act and omission (and doing and allowing) are attempts to sort or classify particular kinds of acts. What they have in common is that they are agent-agnostic. They are theoretical terms, coined to do theoretical work. The same cannot be said of withdrawing and withholding life-saving treatment, which refer to particular facets of medical practice and, as we have argued, are agent-relative.

An essay by Jecker and Emmanuel provides further support for our view. They suggest that the practice of medicine should not be equated with the use of-or specific acts of-medical treatment. Rather, they say:

medicine is more properly thought of as developing and implementing a plan of caring for a patient, a plan that may incorporate both administering treatments and refraining from administering treatments. [40]

The implication of this stance, and our suggestion that withdrawing and withholding life-saving treatment are practices, is that any prima facie "omission" is actually the result of an act or acts. Indeed, they are not mere results of the broader endeavor, but part and parcel of that endeavour. After all, decisions not to treat never constitute the entirety of any one patient's care. This view-namely, that particular decisions to withdraw or withhold life-saving medical treatments should not be evaluated in isolation from the patient's care plan as a whole-represents a direct challenge to the ceteris paribus clause required by the ET. It is no longer clear that the ET can be maintained for withdrawing and withholding life-saving treatment, given that each instance is accompanied by a specific care plan tailored to meet the needs of the particular patient. Furthermore, the type of care that a patient requires following the 
withdrawal of treatment tends to significantly differ from that required by a patient from whom treatment is being withheld-not least because the former tends to occur after a period of time during which the patient has been receiving intensive care, while the latter tends to occur in emergency contexts.

Further reflection on the withdrawing and withholding of life-saving treatment reveals additional differences between them. Certainly, every case of withdrawing life-saving treatment follows some period of time in which that treatment was provided. The same cannot always be said of withholding life-saving treatment. ${ }^{20}$ Furthermore, one might attach moral significance to the fact that those who decide to withdraw treatment from a patient have typically provided that same treatment and care to the patient until the point of withdrawal. Given that an important facet of medical morality is the imperative to do no harm, one can appreciate that healthcare professionals may be more reluctant to withdraw, as opposed to withhold, certain medical treatments, particularly when they are maintaining some form of status quo. $^{21}$

Citing a presentation by Mildred Solomon [67], ${ }^{22}$ Margaret Somerville seems to think that healthcare professionals' reluctance to withdraw treatment has an ethical purpose: it keeps one "from becoming insensitive to the seriousness of withdrawing treatment and making it too easy" [68, p. 363]. Her position seems to be predicated on the view that "withholding-of-treatment cases are much more ethically and morally clear cut than withdrawal ones" [68, p. 91]. However, the point seems debatable at best. There will, of course, be cases of withholding care in which the patient's impending death is a near certainty; yet there will also be plenty of cases in which there is some degree of prognostic uncertainty. By contrast, a patient who is considered a candidate for the withdrawal of life-saving treatment is likely to have a fairly clear prognosis. Indeed, such thinking lies behind the aforementioned suggestion that it may, on the whole, be preferable to withdraw life-saving treatment rather than withhold it [66]. As a result, it may be that the greater degree of reluctance to withdraw rather than withhold life-saving treatment serves relatively little (moral) purpose. It may also be that our greater reluctance to withdraw treatment is simply an iteration of our reluctance to actively intervene with the person of another-particularly when doing so causes or allows death to occur-regardless of the moral purpose, aim, or goal that the intervention is designed to bring about (e.g., bringing an end to suffering). Nevertheless, given that one entails a prior attempt at treatment

\footnotetext{
20 Jecker and Emanuel make a similar point [40], while Fred Frohock discusses the importance of the history of decision-making [61].

21 Analytic moral philosophy and applied ethics tend not to recognize that moral responsibilities can deepen as a result of our interactions with one another. However, this is not the case for the ethics of care, nor is it true for more continental moral philosophies, such as those that emphasize ethical demand (e.g., K.E. Løgstrup), the face of the other (e.g., Emmanuel Levinas), and the I-Thou relationship (e.g., Martin Buber). We have no space to go into detail here; so suffice it to say that such perspectives could well be used to suggest that the simple fact of prior treatment generates an increased moral obligation toward the patient on the part of those responsible for such treatment.

22 Solomon subsequently published an article on professionals' views of life-sustaining treatments [8]. However, the sentiment is not contained within it, and we have not found it elsewhere.
} 
there will be less prognostic uncertainty in cases of withdrawing than in cases of withholding. This disparity in prognostic uncertainty has ethical significance and is likely to impact on the way in which the practices of withdrawing and withholding life-saving medical treatment are-and ought to be-structured.

Perhaps the most important difference between the practices of withdrawing and withholding life-saving treatment is, then, their respective temporal structures. First, unlike decisions to withdraw life-saving treatment, decisions to withhold life-saving treatment often occur across short periods of time and in emergency situations. While this is not always the case-treatment can be withheld as a result of a particular decision made after a period of discussion and reflection-it may be that the abbreviated temporal structure sets a particular tone.

In emergency situations, healthcare professionals have a high degree of autonomy - the patient is usually unconscious, while both family members and any documentation regarding the patient's wishes are unlikely to be available. In such cases, clinicians must make decisions in accordance with their professional judgment and the clinical facts they are presented with. Such decisions are very unlikely to be challenged, and, in any event, there is little to no time for extended discussion of conflicting points of view. The restricted time frame in which decisions to withhold lifesaving medical treatment must often be made sharply contrasts with the protracted process by which decisions to withdraw life-saving treatment are usually reached. Such decisions can involve extensive discussion, reflection, and debate, taking place over a number of days, if not weeks. ${ }^{23}$ They may also include the patient, a range of healthcare professionals, the patient's family, and, in some cases, ethicists and lawyers. Withdrawing life-saving treatment should not, then, be considered an act or, at least, not a specific, temporally located act. Rather, what is required-which is to say, what is entailed-in the withdrawal of care is a complex set of actions and interactions. Indeed, Robert Zussman suggests that "few decisions to limit medical treatment are discrete events" and that representations to the contrary are often dramatizations or, perhaps more accurately, case narratives (re)constructed in retrospect [62, p. 102].

Other (non-emergency) cases of withholding life-saving treatment also have features that differentiate them from those in which such treatment is withdrawn. While they may take place over time and a range of other people may be involved in the decision-making process, they involve considering questions in advance of any pressing need for their resolution. Thus, they might concern decisions not to attempt resuscitation, decisions not to provide antibiotics if and when the patient contracts an infection, or decisions to remove a pacemaker. As such, while death may well be a consequence of the decision being made, it is rarely an immediate consequence. Such cases contrast with decisions to withdraw life-saving medical treatment, where death is usually expected to occur in a relatively short period of time. In our view, the extended time available for decision-making, coupled with the relative proximity of death after the decision is made and implemented, means that withdrawing

\footnotetext{
23 Or, as a number of recent United Kingdom court cases concerning the withdrawal of life-saving medical treatment from children have shown, such decisions can take place over a matter of months.
} 
life-saving medical treatment presents clinicians with more challenges than does withholding life-saving treatment in both emergency and non-emergency contexts. This point may go some way toward explaining the differing dispositions of professionals with regard to withdrawing and withholding life-saving medical treatment.

\section{Conclusion}

In this paper, we have sought to challenge the validity of the ET in relation to withdrawing and withholding life-saving medical treatment. To this end, we have drawn on the idea that a proper ethical analysis of withdrawing and withholding life-saving treatment should not presume that they are particular acts or even decisions, but rather should regard them as parts of medical practice, if not practices in and of themselves. In this context, it is difficult to think of actual cases in which there is no legitimate moral difference between withdrawing and withholding life-saving medical treatment, other than the bare fact that withholding such treatment involves omitting to provide it while withdrawing such treatment involves acting to discontinue it. Furthermore, even if a pair of comparable cases could be identified, they would reveal very little about the ethics of withdrawing and withholding life-saving medical treatment more generally. Blanket statements about the moral equivalence of withdrawing and withholding are of little use. What is required is a more specific focus on particular arenas of medical practice; examples include adult and neonatal end-of-life and palliative care, emergency medicine, and the appropriate use of cardiopulmonary resuscitation in a variety of contexts. A detailed consideration of the ethical issues that arise in each of these domains is required if one is to properly establish the moral pertinence of withdrawing and withholding life-saving treatments in any given case.

Acknowledgements This paper was written with the support of ENDCARE, an Erasmus+ funded project on ethics and care at the end of life.

Funding EU ERASMUS+ Programme Agreement No. 2015-1-MT01-KA203-003728: Harmonisation and Dissemination of Best Practice - Educating and alleviating the concerns of Health Care Professionals on the proper practice of end of life care (ENDCARE).

\section{References}

1. Orentlicher, David. 2001. Matters of life and death: Making moral theory work in medical ethics and the law. Princeton: Princeton University Press.

2. Fins, Joseph J. 2006. A palliative ethic of care: Clinical wisdom at life's end. Sudbury, MA: Jones and Bartlett.

3. Beauchamp, Tom L., and James F. Childress. 2009. Principles of biomedical ethics. 6th ed. Oxford: Oxford University Press.

4. Veatch, Robert M. 2003. The basics of bioethics. 2nd ed. Upper Saddle River, NJ: Prentice Hall.

5. Wilkinson, Dominic and Julian Savulescu. 2014. A costly separation between withdrawing and withholding treatment in intensive care. Bioethics 28: 127-137. 
6. English, Veronica, and British Medical Association. 2008. Withholding and withdrawing life-prolonging medical treatment: Guidance for decision making. 3rd ed. Malden, MA: Blackwell.

7. Berlinger, Nancy, Bruce Jennings, and Susan M. Wolf. 2013. The Hastings center guidelines for decisions on life-sustaining treatment and care near the end of life. 2nd ed. Oxford: Oxford University Press.

8. Solomon, Mildred Z., Lydia O’Donnell, Bruce Jennings, Vivian Guilfoy, Susan M. Wolf, Kathleen Nolan, Rebecca Jackson, Dieter Koch-Weser, and Strachan Donnelley. 1993. Decisions near the end of life: Professional views on life-sustaining treatments. American Journal of Public Health 83: 14-23.

9. Dickenson, Donna L. 2000. Are medical ethicists out of touch? Practitioner attitudes in the US and UK towards decisions at the end of life. Journal of Medical Ethics 26: 254-260.

10. Cartwright, Colleen Maria, Ben P. White, Lindy Willmott, Gail Williams, and Malcolm Holbrook Parker. 2016. Palliative care and other physicians' knowledge, attitudes and practice relating to the law on withholding/withdrawing life-sustaining treatment: Survey results. Palliative Medicine 30: 171-179.

11. Ortner, Sherry B. 1984. Theory in anthropology since the sixties. Comparative Studies in Society and History 26: 126-166.

12. Joseph, Rouse. 2007. Practice theory. In Handbook of the philosophy of science: Philosophy of anthropology and sociology, vol. 15, ed. Stephen P. Turner and Mark W. Risjord, 639-681. London: Elsevier.

13. Bennett, Jonathan. 1995. The act itself. Oxford: Oxford University Press.

14. Schatzki, Theodore R. 2001. Introduction: Practice theory. In The practice turn in contemporary theory, ed. Theodore R. Schatzki, Karin Knorr Cetina, and Eike von Savigny, 10-23. London: Routledge.

15. Fligstein, Neil, and Doug McAdam. 2012. A theory of fields. New York: Oxford University Press.

16. Stevens, M.L.Tina. 2003. Bioethics in America: Origins and cultural politics. Baltimore: Johns Hopkins University Press.

17. Rothman, David J. 2003. Strangers at the bedside: A history of how law and bioethics transformed medical decision making. New York: Aldine de Gruyter.

18. Jonsen, Albert R. 1998. The birth of bioethics. New York: Oxford University Press.

19. Belkin, Gary S. 2014. Death before dying: History, medicine, and brain death. New York: Oxford University Press.

20. President's Commission for the Study of Ethical Problems in Medicine and Biomedical and Behavioral Research. 1983. Deciding to forego life-sustaining treatment: A report on the ethical, medical, and legal issues in treatment decisions. Washington, DC: United States Government.

21. President's Commission for the Study of Ethical Problems in Medicine and Biomedical and Behavioral Research. 1981. Defining death: A report on the medical, legal and ethical issues in the determination of death. Washington, DC: United States Government.

22. Beecher Henry, K., Raymond D. Adams, A. Clifford Barger, William J. Curan, Derek DennyBrown, Dana L. Farnsworth, Jordi Folch-Pi, et al. 1968. A definition of irreversible coma: Report of the ad hoc committee of the Harvard medical school to examine the definition of brain death. JAMA 205: 337-340.

23. Glover, Jonathan. 1977. Causing death and saving lives: The moral problems of abortion, infanticide, suicide, euthanasia, capital punishment, war and other life-or-death choices. Harmondsworth: Penguin.

24. Lamb, David. 1995. Therapy abatement, autonomy and futility: Ethical decisions at the edge of life. Aldershot: Ashgate.

25. Harris, John. 1985. The value of life: An introduction to medical ethics. London: Routledge.

26. Rachels, James. 1975. Active and passive euthanasia. New England Journal of Medicine 292: 78-80.

27. Kamm, Frances Myrna. 1983. Killing and letting die: Methodological and substantive issues. Pacific Philosophical Quarterly 64: 297-312.

28. Lichtenberg, Judith. 1982. The moral equivalence of action and omission. Canadian Journal of Philosophy 12: 19-36.

29. Thomas, Laurence. 1982. Acts, omissions, and common sense morality. Canadian Journal of Philosophy 12: 37-46.

30. Emmerich, Nathan. 2015. What is bioethics? Medicine, Health Care and Philosophy 18: 437-441. 
31. Jecker, Nancy S., Albert R. Jonsen, and Robert A. Pearlman. 2007. Bioethics: An introduction to the history, methods, and practice. 2nd ed. Boston: Jones and Bartlett.

32. Jecker, Nancy S., Albert R. Jonsen, and Robert A. Pearlman. 1997. Bioethics: An introduction to the history, methods, and practice. 1st ed. Boston: Jones and Bartlett.

33. Jecker, Nancy S., Albert R. Jonsen, and Robert A. Pearlman. 2011. Bioethics: An introduction to the history, methods, and practice. 3rd ed. Boston: Jones and Bartlett.

34. Sulmasy Daniel, P., and Jeremy Sugarman. 1994. Are withholding and withdrawing therapy always morally equivalent? Journal of Medical Ethics 20: 218-224.

35. Wilkinson, Dominic, and Julian Savulescu. 2014. A costly separation between withdrawing and withholding treatment in intensive care. Bioethics 28: 127-137.

36. McGee, Andrew. 2015. Acting to let someone die. Bioethics 29: 74-81.

37. Brody, Baruch. 1996. Withdrawal of treatment versus killing of patients. In Intending death: The ethics of assisted suicide and euthanasia, ed. Thomas L. Beauchamp, 90-103. Upper Saddle River, NJ: Prentice Hall.

38. Derse Arthur, R. 2005. Limitation of treatment at the end-of-life: Withholding and withdrawal. Clinics in Geriatric Medicine 21: 223-238.

39. Huddle, Thomas S. 2013. Moral fiction or moral fact? The distinction between doing and allowing in medical ethics. Bioethics 27: 257-262.

40. Jecker Nancy, S., and Linda Emanuel. 1995. Are acting and omitting morally equivalent? A reappraisal. Journal of the American Geriatrics Society 43: 696-701.

41. Kuhse, Helga. 1998. Why killing is not always worse-and sometimes better-than letting die. Cambridge Quarterly of Healthcare Ethics 7: 371-374.

42. Miller, Franklin G., Robert D. Truog, and Dan W. Brock. 2010. Moral fictions and medical ethics. Bioethics 24: 453-460.

43. Steinbock, Bonnie (ed.). 1980. Killing and letting die. Englewood Cliffs, NJ: Prentice Hall.

44. Perrett, Roy W. 1996. Killing, letting die and the bare difference argument. Bioethics 10: 131-139.

45. Rachels, James. 1981. Reasoning about killing and letting die. Southern Journal of Philosophy 19: 465-473.

46. Rachels, James. 1979. Killing and starving to death. Philosophy 54: 159-171.

47. Rachels, James. 1986. The end of life: Euthanasia and morality. Oxford: Oxford University Press.

48. Rachels, James. 2001. Killing and letting die. In Encyclopedia of ethics, 2nd ed, ed. Lawrence C. Becker, Mary Becker, and Charlotte Becker, 947-950. Abingdon: Routledge.

49. Zucker, Marjorie B., and Howard D. Zucker (eds.). 1997. Medical futility and the evaluation of lifesustaining interventions. Cambridge: Cambridge University Press.

50. Woollard, Fiona. 2015. Doing and allowing harm. Oxford: Oxford University Press.

51. Gillett, G.R., S. Honeybul, K.M. Ho, and C.R.P. Lind. 2010. Neurotrauma and the RUB: Where tragedy meets ethics and science. Journal of Medical Ethics 36: 727-730.

52. Christakis, Nicholas A. 2001. Death foretold: Prophecy and prognosis in medical care. Chicago: University of Chicago Press.

53. MacIntyre, Alasdair. 1988. After virtue: A study in moral theory. 2nd ed. Notre Dame: University of Notre Dame Press.

54. Christopher, Higgins. 2010. Worlds of practice: MacIntyre's challenge to applied ethics. Journal of Philosophy of Education 44: 237-273.

55. Lutz, Christopher Stephen. 2012. Reading Alasdair MacIntyre's after virtue. London: Continuum.

56. Stern, David G. 2003. The practical turn. In The Blackwell guide to the philosophy of the social sciences, ed. Stephen P. Turner and Paul A. Roth, 185-206. Malden, MA: Blackwell.

57. Winch, Peter. 1990. The idea of a social science and its relation to philosophy. 2nd ed. London: Routledge.

58. Andre, Judith. 2004. Bioethics as practice. Chapel Hill: University of North Carolina Press.

59. Pleasants, Nigel. 2000. Winch, Wittgenstein and the idea of a critical social theory. History of the Human Sciences 13: 78-91.

60. General Medical Council. 2013. Good medical practice. London: General Medical Council.

61. Frohock, Fred M. 1986. Special care: Medical decisions at the beginning of life. Chicago: University of Chicago Press.

62. Zussman, Robert. 1992. Intensive care: Medical ethics and the medical profession. Chicago: University of Chicago Press.

63. Anspach, Renée R. 1993. Deciding who lives: Fateful choices in the intensive-care nursery. Berkley: University of California Press. 
64. Cassell, Joan. 2005. Life and death in intensive care. Philadelphia: Temple University Press.

65. Templeman, Jenni S. 2015. An ethnographic study of critical care nurses' experiences following the decision to withdraw life-sustaining treatment from patients in a UK intensive care unit. $\mathrm{Ph} . \mathrm{D}$. dissertation, University of Salford. http://usir.salford.ac.uk/36188.

66. Jean-Louis, Vincent. 2005. Withdrawing may be preferable to withholding. Critical Care 9: 226-229.

67. Solomon, Mildred. 1992. Health care professionals and treatment at the end of life. Presentation at the annual meeting of the American Society of Law and Medicine, Cambridge, MA, October 1992.

68. Somerville, Margaret. 2001. Death talk: The case against euthanasia and physician-assisted suicide. Montreal: McGill-Queen's University Press.

Publisher's Note Springer Nature remains neutral with regard to jurisdictional claims in published maps and institutional affiliations.

\section{Affiliations}

\section{Nathan Emmerich ${ }^{1,2,3}$ (D) Bert Gordijn ${ }^{2}$}

Bert Gordijn

bert.gordijn@dcu.ie

1 Medical School, Australian National University, Canberra, Australia

2 Institute of Ethics, Dublin City University, Dublin, Ireland

3 School of History, Anthropology, Politics and Philosophy, Queen's University Belfast, Belfast, UK 